\title{
Multiple Media Use in Organizations: Identifying Practices Leading to an Alignment Paradox
}

\author{
Keith Munkejord \\ Norwegian University of Science and Technology, \\ Trondheim, Norway
}

Keith.munkejord@svt.ntnu.no

\begin{abstract}
A case study was conducted in a department of a Fortune 500 company to explore multiple media practices. Existing research has been dominated by a focus on the use of single media, and the valuable insights and knowledge gained in this research largely ignore the characteristics and consequences of multiple media use in organizational settings. Three interrelated practices were identified as important for multiple media use patterns: media cycling practices, fluid interdependent media practices, and puzzle zone practices. Finally, an alignment paradox evolved, suggesting that the patterned use of multiple media produce diametrically opposed work practices that may significantly influence the core business.
\end{abstract}

Keywords: Multiple media, Structuration, Case study, Grounded Theory

\section{Introduction}

The use of information and communication technologies (ICTs) in organizations has become increasingly complex and fluid. Both leaders and co-workers combine the use of different technologies to communicate (Belanger \& Watson-Manheim, 2006), and to coordinate complex tasks with a high degree of interdependency (Kellogg, Orlikowski \& Yates, 2006). Structuring individual work as well as coordinating and aligning work practices on the group level becomes a challenging endeavour in the continuous changing work environment, in which multiple media is used increasingly to communicate and conduct work. This paper aims at elaborating the limited knowledge we have regarding the characteristics of multiple media use patterns and the consequences that may follow from this use. Existing research has been dominated by a focus on the use of single media, such as the use of cell phone and short messaging service (SMS) (Ling, 2005), instant messaging (Quan-Haase, Cothrel, \& Wellman, 2005), video conferencing (Martin \& Rouncefield, 2003), groupware (Tam \& Greenberg, 2006; Vreede \& Guerrero, 2006), email (Belloti, Ducheneaut, Howard, Smith, \& Grinter, 2005), or the comparison of different media (Si-

Material published as part of this publication, either on-line or in print, is copyrighted by the Informing Science Institute. Permission to make digital or paper copy of part or all of these works for personal or classroom use is granted without fee provided that the copies are not made or distributed for profit or commercial advantage AND that copies 1) bear this notice in full and 2) give the full citation on the first page. It is permissible to abstract these works so long as credit is given. To copy in all other cases or to republish or to post on a server or to redistribute to lists requires specific permission and payment of a fee. Contact Publisher@InformingScience.org to request redistribution permission. vunen \& Valo, 2006). The valuable insights and knowledge gained in this research largely ignores the characteristics and consequences involved in the use of multiple media in organizational settings.

In this paper the terminology "multiple media" is used to describe sequential use (i.e., email followed by phone) and concurrent use (i.e. email and phone 
used at the same time), following the terminology of Belanger and Watson-Manheim (2006). The use of multiple media in organizations is partly unexplored, and several researchers have called for work within this area (Stephens, 2005; Stephens, Browning, Sørnes \& Sætre, 2005; Woerner, Orlikowski \& Yates, 2004). The expectation that new media will continuously and rapidly replace existing 'old' media may partly explain why media combinations have not been studied. Second, few data sets exist on the use of multiple media, and finally, theoretical guidance for this work is meager (Stephens, 2005). If the use of single media is no longer isolated acts, but intertwined as multiple media activities both sequentially and concurrently, we as researchers should not approach these media and their users as isolated acts either.

In this article the characteristics and consequences of multiple media practices are examined through a qualitative case study conducted in a department of a Fortune 500 company. First, theoretical perspectives on the use of multiple media are introduced. Second, a structurational perspective will be presented for understanding the consequences this use may produce. Third, a description of the research method and the results follow this, and finally, theoretical and practical implications of the results are discussed.

\section{Literature on Multiple Media Use}

Short, Williams, and Christie (1976) proposed that combining different media may be proportioned through a "communication diet" in which "An increase in one component may result in all sorts of adjustments, in the amounts of the other components and in the mix and sequencing of the three [written, face-to-face (FtF), and telecommunication]" (p. 143). This use may influence both the interaction between people and outcome of organizational tasks. Further, different media have varying capacities for coping with ambiguities, as well as handling the fluid character of interpretations. Combining media that are both "lean" and "rich" may be necessary to obtain the relevant information that is needed in an organization. This media choice is influenced by the sensed ambiguity of the message, symbolic cues, and situational constraints (Trevino, Lengel, \& Daft, 1987). Characterizing different media as varying in degree of richness (lean vs. rich) has been criticised for being overly deterministic, neglecting the importance of social and situational factors, and how these factors may influence media user behavior (Sørnes, 2005).

These social and situational factors may also trigger multiple media use patterns that serve as a form of "redundancy insurance", on the communication of importance, expectance, and needs of ambiguous requirements (Sitkin, Sutcliffe, \& Barrios-Choplin, 1992). Redundancy insurance results in use patterns that aim at increasing the likelihood that the message gets through by combining media. You might choose to send an email initially, followed by a phone call to make sure that the designated receiver has read or understood the intended message. Further, "suboptimal media choices" may be chosen as part of larger communicative strategies, and "sequences or combinations" of media may be better for communicative efficiency (Walther \& Parks, 2002). This bears resemblance to the concept "satisficing", emphasizing that our choices of media are sub optimized rather than holdouts for perfect decisions (Stephens et al., 2005). Task complexity, contextual or situational constraints, and availability of media are three factors that may influence how combining media is necessary to work effectively in organizational settings.

Nardi and Whittaker (2002) propose the design of media ecologies in which the nature of work as well as contextual determinants will determine a particular mix of media. These media ecologies consist of people, practices, and technologies that are specified according to a particular set of circumstances. According to the authors, these ecologies provide cost-effective solutions for communication. One should devise an "appropriate mix of FtF and other media depending on the work, its temporal sequence, the context, and the distances to be travelled" (p. 102). Nardi and Whittaker (2002) states that a paradox might arise as a consequence of diverse and distributed 
Webs of relationships embedded in increasingly complex organizations and social networks that are dependent upon both sophisticated communication technologies and human interaction in the form of face-to-face communication.

While Nardi and Whittaker (2002) use media ecologies to describe the relationship between individuals and the environment in which the use of multiple media takes place, Woerner, Orlikowski and Yates (2004) describe the assortment of technologies available in an organization labelled as a "media toolbox". Media "can be used alone or combined, for individual or concurrent conversations, depending on what needs to be communicated and accomplished within a group at particular times in particular places" (p. 25). This use is based on the organizational members' purpose of the communication, as well as the technology that is available. However, the authors point out that availability and communication routines will not automatically determine the use. The media toolbox may therefore be seen as a label describing the multiple media that are available in an organization, and that the patterns of multiple media use will vary according both to contextual demands as well as the media available in the "toolbox".

Focusing on the characteristics of media combinations, Stephens (2005) introduces multiple media use in organizations to capture both simultaneity (i.e., multitasking) and sequentiality (i.e., FtF followed by e-mail). Her findings show that the Web is used most frequently and for information reasons. Entertainment reasons are a predictor for the use of a single medium, while media combinations will occur in situations where persuasion and documentation are of importance. $\mathrm{FtF}$ communication is the medium used most often secondly in a media combination. Finally, FtF will be used for persuasion, while e-mail is primarily used for documentation. Belanger and WatsonManheim (2006) state that combinations of media are used to accomplish specific communication goals, and extend the research of Stephens (2005) by identifying two "primary structures" with subtypes for combining media. The first is sequential combinations of multiple media in which "two ore more different media are used in sequence, i.e., one following another, and therefore [this use of multiple media] occurs over time". The second is concurrent combinations in which two or more media are used at the same time. A sequential combination consists of a serial and a complementary subtype. The serial subtype refers to a combination of media, such as e-mail and phone, with a purpose of sending the same message because of lack of expected response. The complementary subtype refers to activities that require the use of multiple media to reach different goals within the same activity.

The concurrent combination of multiple media contains three subtypes: (1) Redundant, in which several media are used to send the same message over time; (2) Independent, in which two or more different collaborative activities are approached with two or more media; and (3) Complementary, when two or more media are used at the same time for one collaborative activity. Altogether, Belanger and Watson-Manheim (2006) identify both structures underlying the use of multiple media, as well as conditions "under which specific combinational structures are invoked and the more general communication goals of the senders" (p. 308). They identify two sets of conditions - one set connected to the "media themselves," such as availability and perceived capability of the media, and the other set related primarily to contextual factors such as message urgency and message salience.

Summing up, recent research has documented both sequential and concurrent use of multiple media in organizations, reasons for using multiple media, a toolbox approach for describing the assortment of media available, designing ecologies for "structuring" multiple media use, and, finally, conditions and structures related to multiple media use. The research reviewed shows that we have limited knowledge about multiple media use patterns and practices. In this article, the importance of clarifying the difference between the concepts "structure" and "pattern" related to multiple media use is emphasized. The term "structure", according to Merriam Webster Online, commonly refers to "something arranged in a definite pattern of organization". This definition 
implies a "static" view of structure. Belanger and Watson-Manheim (2006) do not define their use of the term "structure", but they describe it as underlying multiple media use, hence evoking connotations to something stable and static. The conditions, as they see it, put in effect or invoke these "structures."

In this paper, I will focus on what characterizes multiple media use patterns and how these are related to practices in specific contexts. Multiple media use approached from such a perspective implies a more dynamic approach. One way of defining "pattern", as defined by Merriam Webster Online, might be to understand it as a "chance configuration". The term "pattern" understood this way refers to configurations that can be identified, but implies that the factors leading to these configurations are non-linear and too complex to understand with research approaches detached from the user context. Further, these patterns will be related to the structure concept placed in a structurational perspective, in which the structure is approached more dynamically. The shortcomings in existing research provoke the first research question: What are the characteristics of multiple media use patterns?

\section{A Structurational Perspective on Consequences of Using Multiple Media}

While it is important to explore the characteristics of multiple media use patterns and how these are related to multiple media use practices, the consequences of this use is unexplored. These multiple media use patterns and practices may influence both pre-existing and emerging structures in work settings. The structurational approach introduced by Giddens (1984) is considered a good framework for understanding "how users' interactions with IT evolve, what the implications of these interactions are, and how we can try to deal with their intended and unintended consequences" (Pozzebon \& Pinsonneault, 2005; p. 1356). Several researchers have used a structurational framework to understand the use of technologies in organizations (DeSanctis \& Poole, 1994; Majchrzak, Rice, Malhotra, King, \& Ba, 2000; Orlikowski, 1992, 2000; Peters, 2006; Pozzebon \& Pinsonneault, 2005; Stephens et al., 2005).

The structurational perspective proposes that structure is organic and develops in specific experiential contexts. Structures are both the medium and the outcome of actions (Fuchs, 2003). These systems are "re-creative" and do not exist outside actions. The structures that emerge serve as guiding principles both for interactions and interpretations (Sandfort, 2003, p. 609). Structures may evolve unintentionally and can, thus, both constrain and enable individual actions. Although individuals will "reflexively monitor" their actions, unintended consequences of actions still occur, such as "unacknowledged conditions" of future actions (Fuchs, 2003).

The organic and re-creative nature of structures (Fuchs, 2003; Sandfort, 2003) implies a dynamic and continuous change in both technology and use patterns (Orlikowski, 2000). Practices that evolve will only achieve temporary "stabilization" because technology continuously redefines and changes use patterns, and the context around these patterns keeps changing. Orlikowski (2000) proposes a practice-oriented understanding of "the recursive interaction between people, technologies, and social action" (p. 405). She focuses on emerging structures in the recurrent interaction with technologies. "This view starts with human action and examines how it enacts emergent structures through recurrent interaction with the technology at hand" (p. 407). Orlikowski (2000) labels this a "practice-based extension" to the existing structural models of technology and describes them as "technologies-in-practice". The increased complexity characterizing technology-mediated work requires more standardized and interdependent artefacts. 


\section{The Challenge of Alignment}

Rice and Schneider (2005) describe how new organizational technology may alter individuals' work practices as well as higher-level organizational processes. These often involve new cognitive work practices that may result in conflicts and misalignments, requiring "effort on the part of the individual to cope, interpret, adjust and resolve" (p. 1). These misalignments closely connected to technology use have been approached and understood as

1. Cycles of misalignments gradually dissolved and aligned over time (Leonard-Barton, 1988);

2. Modifications through windows of opportunity resulting in alignments through discontinuous adaptations (Tyre \& Orlikowski, 1994); and

3. Discrepant events occurring continuously and sporadically, unexpectedly challenging existing structures. As such both pre-existing structures and emergent structures may create new discrepant events challenging alignment (Majchrzak et al., 2000).

According to Majchrzak et al. (2000), studies of technology use should be embedded within specific organizational contexts. The use of multiple media may create different unpredictable patterns of multiple media use from a structurational perspective that may challenge individual and shared work practices. Belanger and Watson-Manheim (2006) highlight the importance of addressing what consequences emerge from the use of multiple media, especially related to "complex work environments". Current research has not yet focused explicitly on the consequences multiple media use may produce in such environments. These shortcomings trigger a second research question: What characterizes the consequences evolving from multiple media use patterns?

\section{Research Methodology}

An inductive approach addressed both characteristics and consequences of using multiple media in organizations. Unstructured interviews, participant observation, semi-structured interviews, and intranet browsing produced multiple data. This section describes the setting and the characteristics of the work practices, provides an outline of the data collection process, presents grounded theory as the adopted analytical approach, and finally outlines the analytical procedures performed.

\section{Setting and Work Practices}

The fortune 500 company in this study, referred to as CKW, is an integrated oil and gas company with activities spread internationally. A strategic sample consisting of high-end users of technology in one 12 member operational department, referred to as OPCOM, was selected for this case study. The department's core business is global sales and transport of chemical raw material. The participants work in a hybrid-work environment with colleagues both co-located and distributed. The department works within sales and logistics with customers on a global market characterized by a high-paced environment with employees placed both in cubicles as well as designated offices. These cubicles have a low-profile privacy panel as part of configurations where several desks are linked together. The privacy panels provide some workspace delineation, while still allowing for both visual and verbal lines of communication. Within the department, three different teams work both within the single team as well as cooperating with the others: sales, logistics, and back office.

The work practices are highly integrated. Business effectiveness is based on the successful integration within and between the teams. The overall business goal is arriving at an optimal match 
between the transport capacities of the different ships internationally and the product volume needed collectively from customers. Such match increases sales and reduces the transport costs. The employees' effective exchange of information by using multiple media is necessary to stay updated on different tasks - such as opportunities and challenges related to transport, changes in customer requests and deliverances, stock status, as well as potential changes and postponements. Operational meetings are held twice a week. These are pivotal in structuring and aligning the collective bits and pieces of information caused by multiple media on the individual level. Spontaneous meetings and discussions in small clusters also occur within and between teams. Finally, infrequent meetings take place about departmental or organizational issues.

The different media used in OPCOM are: FtF communication in open landscape, meetings, and other interpersonal situations; personal and shared email systems; multiple databases - team specific and general; phone and cell phone, including SMS; a so-called message manager (digital fax system); the Internet and an intranet, as well as the occasional use of NetMeeting and telephone conferences. Finally, the Microsoft Office package was used frequently to construct, revise or comment on calculus sheets, presentations, and documents that were included in databases or sent as attachments in emails.

\section{Data Collection}

OPCOM consists of 12 employees working in three different teams: Logistics, Sales, and back office. All 12 employees volunteered to participate in the study. The data was collected from April to September 2005. The respondents collaborated daily with colleagues within other parts of CKW both nationally and internationally, although these colleagues are not among the respondents in this case study. The sample consisted of 6 male and 6 female respondents, varying from 30 to 62 years, with bachelor and master degrees in engineering and economics. Their duration of employment in OPCOM varied from 3 weeks to 6 years.

\section{Research Process}

The study focused on the everyday practices in OPCOM. The data collection was exploratory in nature and combined unstructured interviews, participant observation, semi-structured interviews, and intranet browsing. First, unstructured interviews were used in the early phase to gain descriptions about the core business, market position, customers, suppliers, collaborate partners, internal and external communication networks, types of media used and for what purposes, and the core functions on the individual and team level. Second, context based unstructured interviews were conducted with all the members in OPCOM on multiple occasions to receive thick descriptions about the situations and events emerging continuously. It was expected that it would be easier to receive thick descriptions while these unfolded compared to at a later stage. The unstructured interviews also clarified the understanding of events and situations resulting from prior interactions, as well as challenges due to business specific language not easily understood by outsiders. According to Esterberg (2002; p. 89), the unstructured interviews "tend to be more spontaneous and free-flowing, with topics arising from the situation or behaviour at hand." Third, semi-structured interviews were conducted with all the respondents during the last 4-6 weeks of the datacollection period (Breakwell, Hammond \& Fife-Schaw, 1997; Robson, 1997). These interviews lasted 40-60 minutes, and were conducted to elaborate the emerging analytical categories suggested by the continuous analysis of the multiple datasets collected throughout the data collection period using Grounded Theory. All the interviews were taped and transcribed.

Further, participant observation was conducted from a designated cubicle, by sitting in on meetings, shadowing individuals, attending the spontaneous clusters of people solving operational and analytical tasks, participating in the cubicles, and in a staff restaurant. Participant observation 
provided hands-on and contextual grounded descriptions of the multiple media practices in OP$\mathrm{COM}$, both in terms of individual practices and the intersection of practices collectively. Often the specific details noted through participant observation were used to trigger more specific descriptions from respondents through unstructured context based interviewing immediately afterwards. In addition, information from the Web describing the core business was reviewed in order to receive a deeper understanding of the practices in OPCOM.

The data collection cycled between interviewing and observing, aligned with the purpose of using the grounded theory approach to focus the research as it evolved during the data collection period (Glaser \& Strauss, 1969). The qualitative software QSR Nvivo7 was used to administrate the multiple datasets and analysis. Often and regularly the participants were briefed and debriefed about the equipment used, issues related to the topics, and degree of intimacy, confidentiality, and anonymity. Conducting research in this department implied a continuous reflexive process of positioning oneself and taking multiple research decisions "on the spot". This was due both to the high-paced work practices as well as the complexities involved in understanding multiple media use in the different work contexts within OPCOM. Reflections concerning the continuous developing relations between the researcher and the participants were registered in order to understand how the respondents work practices were approached and analyzed. All the data were collected, transcribed, and analyzed by the author.

\section{Grounded Theory: The Analysis in Practice}

Grounded Theory moves from incidents or experiences. An elaborate process unfolds resulting in abstract conceptual categories that explain the data, through the constant comparative method for coding (Charmaz, 2003; Glaser \& Strauss, 1967). Charmaz (2003; p. 99) presents the analytical process: "Starting with line-by-line coding, thereafter initiate focused coding synthesizing and explaining larger segments of the data collected. Then, finally, the movement from the focused codes to conceptual categories reflecting themes and patterns in several codes."

This focus on practice provides an understanding of "multiple layers of meaning of their actions", such as their: "(1) stated explanation of his or her action, (2) unstated assumptions about it, (3) intentions for engaging in it, (4) effects on others, and (5) consequences for further individual action and interpersonal relations" (Charmaz, 2003; p. 90). Simultaneous collection of observational and interview data yield more complete understanding of interactions and practices (Prus, 1996). Within Grounded Theory, the ideal is a cycling between data collection and analysis that produces theoretical insights (Glaser \& Strauss, 1967; Locke, 2001). This study abided by those guidelines throughout. Nvivo 7 served to analyze the multiple datasets. The structural features in Nvivo7 supports the analytical steps as described in Grounded Theory (Charmaz, 2003). The analysis followed similar procedures as those presented by Kellogg et al. (2006), cycling between the multiple datasets and in-depth readings of these, iterative coding of recurring themes in the dataset, and building categories that would help to identify multiple media use in OPCOM.

\section{Findings}

This study aimed at exploring the characteristics of and consequences evolving from multiple media use patterns. The review of the literature highlighted that knowledge exists about the structural properties of multiple media use, but showed that we have limited knowledge about what characterizes multiple media use patterns and practices. The review also identified that we have very limited knowledge about the consequences that might evolve from this use. Finally, existing research on multiple media use has primarily focused on the individual level. 
The main findings in this study are three interrelated practices important for multiple media use patterns on both the individual and collective level: media cycling practices, fluid interdependent media practices, and puzzle zone practices. Finally, an alignment paradox was identified, suggesting that the patterned use of multiple media produces diametrically opposed work practices as a consequence. The findings will be presented briefly before each of them is elaborated.

1. Media cycling practices contain three conditions for multiple media use: access dependent, perceived urgency, and task complexity. These three conditions result in five different multiple media use patterns: rotation strategy, monitoring, coercive use, habitual use, and redundancy insurance. Media cycling practices are positioned on the individual level.

2. Fluid interdependent media practices contain contradictory, interruptive, and sub-optimal use patterns. These practices are positioned on the collective level.

3. Puzzle zone practices contain clusters of people in formalized meetings or informal settings trying to solve challenges through aligning multiple bits and pieces of information according to goals and strategies. These practices are positioned on the collective level.

4. The coexisting, co-evolving, and interrelated character of these practices produced an alignment paradox. Alignment refers to the proper positioning or state of adjustment of the different parts in relation to one another (individual and collective practices). A struggle ensues between the act of aligning and the state of being aligned. The Alignment Paradox shows that the normal state in OPCOM is the continuous act of aligning; alignment is only momentary.

The findings were evident among all the participants in the study and underlined by the multiple datasets included in this study. In the following these main findings will be elaborated. The quotes that will be used to illustrate the main points are primarily based on the semi-structured interviews conducted in the final phase of the data collection period. These interviews elaborated the insights and analysis of the observations as well as the unstructured interviews conducted throughout the data collection period.

\section{Media Cycling Practices}

A cycling process characterized the requirement of using multiple media to communicate and solve tasks in OPCOM. Cycling referred to the fluid integration of media and their order of use. The use of multiple media occurred both sequentially and concurrently. Information received through a single email or by phone by any member within OPCOM could alter the use of multiple media both individually and collectively to solve the emerging tasks. These patterns of work were identified and labelled media cycling practices, and they were initiated on the individual level. Three conditions were identified as important for multiple media use patterns. These were access dependent, perceived urgency, and task complexity. These three conditions resulted in five different multiple media use patterns: rotation strategy, monitoring, coercive use, habitual use, and redundancy insurance. In the following discussion, the three conditions will be elaborated before the five patterns are presented.

\section{Access dependent condition}

The access dependent condition refers to the extent to which one person is able to reach another person through single or multiple media. Colleagues outside OPCOM but within CKW, distributors, and customers could be accessed differently from time to time. That is, colleagues that were attending a meeting could be accessed more easily by SMS compared with e-mail after noticing that the targeted person did not answer phone calls. Access was based on the use of multiple me- 
dia. In this context, access was the driving force that contributed to progress in tasks. One participant as part of the sales team illustrated this in one of the unstructured interviews:

I sent a colleague an SMS (short message service) in London earlier today so that I did not disturb him in a meeting. I asked him to call me when he had time available. When there are things I might use two hours to find out, that will not take more than two seconds for a colleague to answer, then we disturb each other.

Access was a key driver among all the participants in OPCOM as to uphold progress in tasks individually. Discussions related to clarifying received content and purposeful ways of accessing others was observed frequently among the respondents. In one such situation a member of the sales team approached a colleague to ask for his advice on how to best gain access to one of the suppliers they work with internationally. The colleague within the same sales team replied: "I guess he has 628 emails in the inbox, so you should call him”. This reply stated clearly that email was considered less effective than making a phone call.

\section{Perceived urgency condition}

The perceived urgency condition refers to how particular work is conducted using multiple media in situations that vary from non-urgent to full-scale crisis. If operational tasks had to be solved immediately, FtF communication was the primary mode of communication followed by cycling between other media to coordinate information and to solve the emerging tasks. This was evident in the comments from one leader:

The tempo is high; the communication is direct and face-to-face. You don't have the time to wait. It is related to the personality of those working in such environments. You get much tougher ways of communicating compared with staff departments, because you have to deal with the operational questions right then and there.

The operational environment OPCOM worked within was characterized by unpredictable situations occurring, forcing them to use multiple media in order to solve these. Typical situations observed were related to information received through emails or by phone that could alter the priorities and execution of existing tasks, and demand the use of multiple media in order to solve these situations. One team member within logistics commented this operational reality in an unstructured interview:

I work in an operative world, and it is the emails or phone calls that influence the operative workday that will be given priority. It might be in Europe, or in Canada or USA. Operative work is priority number one.

Ships being delayed, sales being cancelled, suppliers unable to deliver were situations that would typically require collaborative work among several of the respondents in OPCOM.

\section{Task complexity condition}

The task complexity condition refers to the extent multiple media use was necessary to solve tasks. The cycling between multiple media was observed to be caused by both multiple tasks existing and worked on at the same time, as well as tasks requiring the use of multiple media due to their complexity. This was commented by a member of the sales team:

It is common that I'm writing three emails simultaneously; have three new memos active, and simultaneously doing calculations in Excel. I have at least two excel windows active, and a couple of Explorer win- 
dows with some information from the Internet. And PowerPoint and Adobe Acrobat Reader; so yes, there's many windows activated at once.

This work pattern was observed frequently among all the members in OPCOM, in which multiple media were used both for analytical and operational tasks. These use patterns could also be part of background work that would be included as the backdrop for a phone call or integrated in specific emails. This shows how elaborate cycling between different systems and media sometimes was necessary to handle task complexity. This is illustrated by one member of the logistics team pointed out in one of the unstructured interviews:

I often work with windows in parallel. Often you might have to comment on a document. This may require you to look into the history what has been said previously. Then you have to log into different systems, and in addition you might use internet to see who the contacts are and receive data on this. Afterwards you will coordinate everything into a single email. It is very natural to work this way. It demands that you are able to do several things at the same time.

It was frequently observed that most of the tasks the respondent worked on required collecting information through the use of multiple media: receiving $\mathrm{FtF}$ information from other colleagues, writing emails, making phone calls, as well as cycling extensively between the multiple systems they work with in order to handle and solve the complex nature of many operational tasks.

\section{Multiple media use patterns}

The conditions identified contributed to the multiple media use patterns within OPCOM. More specifically, the conditions were drivers for the multiple media use patterns and connected to these in a non-linear sense.

Table 1: Multiple media use patterns

\begin{tabular}{|l|l|}
\hline \multicolumn{1}{|c|}{ Pattern } & \multicolumn{1}{c|}{ Description } \\
\hline Rotation & $\begin{array}{l}\text { Alteration between multiple media to gain access to peo- } \\
\text { ple and to uphold progress in tasks. }\end{array}$ \\
\hline Monitoring & $\begin{array}{l}\text { Cycling between different media to keep continuous } \\
\text { overview of various processes. }\end{array}$ \\
\hline Coercive use & $\begin{array}{l}\text { Forcing other colleagues to use multiple media to answer } \\
\text { own work related requests. Interruptive in nature. }\end{array}$ \\
\hline Habitual use & $\begin{array}{l}\text { Media combinations that is of a recursive character ver- } \\
\text { sus adaptive according to demands. }\end{array}$ \\
\hline Redundancy insurance & $\begin{array}{l}\text { Increasing the likelihood that the message gets through } \\
\text { by using multiple media. }\end{array}$ \\
\hline
\end{tabular}

\section{Rotation}

Elaborating the multiple media patterns in Table 1, using a rotation strategy between multiple media increased the chance of gaining access. Often, cycling between multiple tasks simultaneously involving different people was observed. Tasks that produced bottlenecks preventing progress or blocked access determined the order of work as well as media choice. A member of the sales team illustrated this: 
Different situations will influence how you use different media. Often phone calls are conducted before mail communication, and the sequence of how things are done, depends on who I am able to access. And when you have multiple tasks at the same time, mail will be sent sometimes, while other times I feel it's nice to take a phone call first. If I can't get hold of the people I need, then I will rotate until I gain access to them.

In operational tasks of great urgency the respondents would rotate between different media until they accessed the targeted person. In work tasks that were of a less urgent nature they would focus on the multiple tasks existing at all times, trying to access those people relevant for these tasks. Although adopting a rotation strategy ensured progress in tasks, it also contributed to highly unpredictable work patterns among the respondents that were access driven.

\section{Monitoring}

Flexibility as an internalised mind-set required effective monitoring by continuously cycling through multiple media during work hours since any given information through the available multiplicity of media could change existing core business. Cycling between multiple media - personal e-mail, shared e-mail, multiple databases, conducting phone calls to customers and suppliers - was necessary. In addition, in coordinating information in the cubicle environment FtF within OPCOM was mandatory to uphold a continuous overview. This was commented by a member of the logistics team in an unstructured interview:

When you have two shared email systems, to private, different databases, and many systems you have to keep track of, you might forget yourself in certain situations. (...) It is a bit hectic and if you miss something while working, it might have big consequences. It might have disastrous consequences. If a ship has nominated a time window for when they will arrive, and something suddenly happens, and they have written an email, and I have not seen it, not reacted to it, then it might have enormous consequences.

The extensive and continuous monitoring of multiple media among the respondents was observed to be very characteristic of their work environment. Although monitoring was considered an important individual activity, observations showed that if they received requests about products they had offered, they would bring the message to other colleagues if it seemed as if these colleagues had not registered this information themselves. All the participants reported that they monitored different media continuously, especially email.

\section{Coercive use}

Both rotation strategies and monitoring triggered coercive communication. Colleagues received a disruptive request to use multiple media to answer their own work related requests. In other words, coerciveness would result in a breakdown of the ongoing work of colleagues that forced them to use multiple media in similar ways to return answers to requests. A sales member commented on this:

In many ways we force one another when we sit in cubicles. Maybe we will ask questions more frequently than necessary, and then we force others in the sense that - if I ask a colleague 'can you check up this or that?'. Then I'll pull this person out of ongoing work. Then I force this person to work the same way as I do with different media 
The coercive multiple media use pattern is caused by the cubicle based work environment, as well as tasks involving the necessity of contributions from respondents belonging to different teams. This coercive pattern is not possible to understand focusing on the individual alone, but occurs as a result of the intersection between several respondents. Coercive multiple media use patterns were frequently observed in OPCOM and arise as a consequence of the physical characteristics of a cubicle based work environment, as well as the continuous information exchange requiring an alteration of existing cycling between multiple media, adapting to the multiple media use pattern required to response to the input needed from the colleague posting the request.

\section{Habitual use}

The continuous changing operational environment in OPCOM also resulted in the need for stability by preserving a day-to-day routine (habitual), commented by a back office team member:

When I arrive at work in the morning, I will activate the intranet and Internet, and then I will activate my e-mail, and the shared areas on Lotus Notes. And then I will read my mail. After that I will read newspapers and news internally. And then I will activate those tasks I work with. And if I have to work on something on the computer I will activate the calculus sheets or documents I will work with.

The habitual multiple media pattern was observed to occur mainly in those periods when the operational activity was low. In many ways one might characterize this as the individual baseline for using multiple media. Another colleague working in the back office team commented on what this habitual use might look like through an unstructured interview:

The first thing I will do is to check the email, then I will switch to SAP and work within this system, and afterwards use email. Usually I will use mail first, then SAP, then back to email, then to the digital fax, then Internet. So I go from mail to SAP to FAX to Mail to fax to SAP. That is how it is.

Although such habitual use pattern might serve as a factor of stability in the unpredictable operational environment, these cycling patterns also appeared to be recursive strategies for monitoring more effectively, while at the same time maintaining a predictable stability in the workflow.

\section{Redundancy insurance}

Many tasks required combining media as a redundancy insurance strategy. A member of the sales team said, "When it is about sales negotiations then I will call, and later confirm the content by email, so that I have a written and confirmed statement regarding the things we have talked about." The media available were not used randomly but utilized according to different media's quality to achieve the communicative purpose, as commented by one co-worker within the logistics team:

Phone and e-mail is perfect when you have daily operations related to coordinating deliverances, price, invoices, and questions related to logistics. But when you have to discuss the development for a specific customer to find out how they perceive things and receive a proper understanding, it is difficult to do this by phone or e-mail.

Observations showed that the employees in OPCOM often discussed whether the understanding of a certain task was aligned, and in those situations operational changes occurred (such as a ship 
being delayed), they would often follow up with a phone call to make sure that the right person had received the email about these changes.

Altogether the multiple media use conditions and patterns as part of the media cycling practices were important to understand how multiple media were used, and how these, in sum, created media cycling practices. Although these were positioned mainly on the individual level, the use patterns would influence the collective practices as well.

\section{Fluid Interdependent Media Practices}

Besides working individually with multiple media, fluid interdependent media practices were identified in the intersection between individual and collective practices. These practices resulted in three different patterns: contradictory use patterns, interruptive use patterns, and sub-optimal use patterns. I will look at each of these three patterns in turn.

\section{Contradictory use patterns}

The tasks in OPCOM were grouped into operational and analytical tasks. Operational tasks were characterized as in part unpredictable. They were related to the sales and logistic challenges that emerged as a result of the interaction through multiple media with suppliers and customers. There was often a necessity to solve the operational tasks immediately, and they were always given priority over the analytical tasks. Analytical tasks were of a more long-term character, involving work processes that required analytical thinking over a longer duration, as well as being related mainly to the structural level in OPCOM (i.e., strategy documents). A member of the sales team comments on this:

It is very much so that the phone rings, things happen all the time, things appear with a high degree of urgency. It is much fireextinguishing and it is incredible frustrating if we are supposed to work with a strategy document or work with an analysis you really have to concentrate on. It is hopeless. ... It is very difficult finding the balance between work that requires thinking and the operational work.

The participants in the study described how they were 'pulled into' the operational work which implied initiating unplanned media practices. The observations indicated that this was common to all of the participants in the study. This created a struggle to find a balance between the operational and the analytical work tasks. The priorities were related to carrying out operational tasks immediately so as not to forget them. In the 'operative world' most agreed that priority went to emails or phone calls influencing a given operational event. This often implied that individual media cycling practices found their way into the fluid interdependent sphere of people working together through multiple media. One leader comments this:

I use too much time on these small e-mails, reading and being informed, which is impossible not to do. They arrive and you have to answer them. And then people ask questions all the time. And then there are continuous postponements; so I am not able to do my work. ... So many tasks keep appearing all the time. This has only gotten worse... I have to use much time to answer.

\section{Interruptive use patterns}

The degree of interruption was related to low versus high involvement tasks mediated through multiple media, identified through continuous monitoring. Low involvement tasks were those that 
were perceived as easy and that did not require analytical effort or the involvement of others to solve. This implied a low degree of interdependency and coerciveness in terms of colleagues' use of media (i.e., confirming participation in a meeting). In contrast, 'high involvement' tasks required analysis involving others, characterized by high degree of interdependency as well as coerciveness. For instance, if a customer asked for the anticipated price of the chemical raw material in the period from the year 2007 to 2010, obtaining the necessary information would require analytical efforts by multiple employees in OPCOM that would in turn trigger different individual practices cycling between multiple media. These high involvement tasks would typically be channelled internally among those situated in the cubicles. They would also influence the working patterns of the others and proceed as FtF coordinated activities. These FtF activities resulted in ongoing interruptions by colleagues and were partly due to the need for updates, clarifications, and answers to questions, as commented by a co-worker within logistics:

We get updated. That is why we scream to each other. That is why it is impossible to use offices. We have to sit in cubicles. We cannot have our own offices. Of course, shouting to each is disturbing, but it is a question of balancing.

Although interruptions were considered more the rule than exception, balance was perceived as important. This also had a paradoxical side to it. In quiet work periods, the members would be more sensitive and have a greater threshold before they asked questions and interrupted others. When the operational temperature raised and the tempo was high, these interruptions would be more frequent and of a higher intensity because of the necessity of dealing with the issues immediately individually, or if required, collectively. Further, these operational intensities emerged in clusters of people replacing one another temporarily, solving time dependent and complex tasks. These intensities occurred on multiple occasions every day while observing the participants in OPCOM.

\section{Sub-optimal use patterns}

The practical and cognitive challenges, structuring the use of multiple and shared databases, created sub-optimal use patterns. The continuous use of multiple media, the intense time pressure, the unpredictability of operational work tasks, and constant interruptions by co-workers provided OPCOM with an immediate focus instead of a long-term orientation. The findings suggest that structuring the shared digital workspaces containing important emails, documents, and procedures were not prioritized because of constant pressure to balance analytical and operational tasks. A member of the sales team comments on this:

The document handling has not been especially good. We have a shared area that is nearly dead. There's no structure or order. It probably has been, but if so, it has not been preserved. The functionality is dependent on each and everyone being focused on putting in what each and everyone thinks is relevant for the others.

In consequence, even more time was spent on finding relevant information and coordinating activities. In turn, this increased the perceived pressure in the working environment and magnified the need to use multiple media as a suboptimal strategy for coordination. The participants recognized that the system should be improved, but lacked a clear vision of how the end product would look. Work tasks constantly changed; time seemed a python; responsibilities and definition of work roles and work tasks gradually changed on the individual level, within the teams, and between teams. The existing systems had lingered for years and much information, once stored, was inactive. These gradual changes in the organization meant that using time to restructure the system was paramount. A member of the sales team comments on this: 
Several should perhaps join together to find out how this system should work, and everyone should agree about how to do it. Because now I feel that someone does it that way, while others do it completely differently. We have to find another flow without loosing information. But I think it would be easier if everyone had agreed on a way to work.

Other difficulties abound. Work habits differed on the shared digital workspaces and perceptions did not coincide concerning the handling of the workload. Part of the paradox was that success hinges upon consensus concerning the structure of this system. No one individual, but all coworkers and the leader must construct the structure and agree on basic principles of sharing. The findings here revealed, however, that this was a core problem and that so far there was no consensus about how to deal with this issue. The result was that there were increased difficulties coordinating information both FtF and through other different media used. One member of the back office team commented that: "Of course it is cumbersome. Especially if something suddenly disappears and you don't know where to look." The lack of common understanding within the shared digital workspace breed chaos and partly explained the accelerated amount of FtF exchange of information for communicative purposes. This was frequently observed as a problem in OPCOM.

\section{Puzzle Zone Practices}

Clusters of members in OPCOM working together to solve emerging challenges are characterized as puzzle zone practices. Puzzle zone practices were solution oriented and involved the assembly of many small bits to gain a picture of the whole. These practices evolved spontaneously or in defined settings (such as the operational meeting). New information detected on the individual level through the cycling of multiple media also spawned puzzle zone practices. These practices evolved as a consequence of the unpredictable nature of information flow, differences of the multiple media use on the individual level, as well as differences in the cognitive understanding and actual use of shared digital systems. The puzzle zones were the main arenas in OPCOM to coordinate and align individual multiple media practices. These could occur spontaneously within or between the three teams to solve emerging problems, as well as in the formally defined arena the operational meetings represented. Puzzle zones served as a control mechanism to manage and solve challenges emerging continuously in the unpredictable work environment. Puzzle zone practices aimed at reaching an optimal match of all the important variables in the operational business environment.

The operational meetings twice a week illustrated the core essence of a puzzle zone and will be used to exemplify here. The meetings coordinated operational information, finalized a monthly program and developed logistic solutions. One member of logistics comments on this:

Life would be brilliant if we were not flexible. Then we would lock our program without being able to edit it. But it is a conscious decision. We are able to change it. If a customer contacts us wishing changes, or a ship is delayed, then we are prepared to change it. But if you change it there will be consequences. And this is why awareness is required. You have to have mechanisms that can locate and capture these consequences fast. If we are not able to do so, then we have a problem with flexibility.

This quote by one logistics co-worker illustrates that workers viewed flexibility to adapt to the changing operational environment as a necessary and important part of OPCOMs core business. It was vital to detect the consequences of changes, and this was done in the intersection between the three practices identified and coordinated through the operational meetings. The core essence of 
work in OPCOM relates to optimizing the intersection between logistics and sales within the designated monthly time frame, leading to a defined deadline. Successful work in the puzzle zone produced profit. The work would cycle between provisional, uncertain, and conflicting conditions. The provisional conditions involved the setup of existing information from the prior month, and the expected outcome of existing processes. The uncertain conditions involved lack of information and the suggestion of unconfirmed program-altering solutions. The conflicting conditions involved two or more parameters in the program that were seemingly impossible to effectuate commercially. A match between the logistic solutions and sales defined the finalized solution. Although the program could be finalized quite early in the program, any changes detected by using multiple media could imply another cycling round between the three conditions. Thus, these are non-linear in the sense that the program does not proceed from the provisional conditions to finalized solution in a linear sense, but may result in cycling between these conditions until the deadline closes the time window to change.

Both "simple" and "complex" interdependent tasks produced this puzzle zone. Although the beginning saw the most frequent cycling between the conditions, changes could occur with great impact at later stages as well. Therefore, operational meetings functioned as an important formalized mechanism. Workers perceived operational work as a continuous flow of changes that were unpredictable and an internalized part of the general mind-set in the department. They served as the primary mechanism to insure necessary flexibility. They allowed the workers to develop an understanding of information and outlined possible actions. They also contributed to synchronizing individual media practices that were otherwise asynchronous because of different individual practices and routines for communicating. The format was conducive to easing negotiation with regards to important parameters that influenced the business area. Workers were co-located in the operational meetings and worked with the same information projected on a screen. The collective $\mathrm{FtF}$ communication in both the landscape as well as in operational meetings served as a "collective memory bank" in which important information overlooked by one, due to the challenge of extensive monitoring and work through multiple media, was remembered by others. The main rationale for these operational meetings was clear: to synchronise all the multiple media activities that were undertaken both individually and collectively.

\section{The Alignment Paradox: Consequences Resulting from the Use of Multiple Media}

The use of multiple media in OPCOM created a constant and continuous tension between preexisting and emerging structures, as alignments are continuously replaced by misalignments. This tension created an alignment paradox, suggesting that the use of multiple media produced diametrical opposed work practices on both the individual and collective level that could significantly influence the core business. The continuous act of aligning implied that it was challenging to match the continuous changes in practices and having technology to support this change. Participants did in part identify alignment challenges as a consequence of being flexible and working under unanticipated operational constraints and intense time pressure. It seemed as if this alignment paradox had evolved due to the increasing number of tasks, their complexity, and the need to use multiple media to work efficiently. It evolved gradually over time and had an ontological and immanent character, not easily identified and subject to control.

The alignment paradox was positioned at the core within OPCOM, both influencing and being influenced by the three different practices identified. Instead of a movement from misalignment to alignment in a linear sense, the organizational members were captured in a tension field between the actual practices characterized by misalignments and the desire to create and maintain alignment. This non-linear tension field created the alignment paradox and was due to continuous 
changes in the media and the ways they were used, difficulties of aligning the collective use of shared digital workspaces in order to communicate and coordinate tasks efficiently, and, finally, the unpredictable nature, flow, and interdependency of operational work both individually and collectively. The pre-existing structures seemed to be an integrated part of emerging structures, and therefore enacted different structures than expected within OPCOM due to the immanent character of the alignment paradox. In the following section the alignment paradox will be elaborated according to the three practices in the following order: (1) media cycling practices, (2) fluid interdependent media practices, and (3) puzzle zone practices.

1) Different characteristics were identified within the context of media cycling practices that contributed to the alignment paradox on the individual level. These were contradictory in nature. First, the practice of monitoring through cycling between multiple media to maintain continuous overview of what happened in the operational environment was diametrical opposed to the necessity of working efficiently with analytical tasks that demanded continuous concentration and focus. Second, the need to reach a balance and stability through habitual media use was in conflict with the fact that unpredictable factors, such as access and task urgency, would determine what tasks that were worked on, in what order, and the types of media used to work efficiently. Third, individual practices of using multiple media were influenced by the coercive nature of media use, in which the organizational members forced other colleagues to use multiple media in similar ways to return answers to requests. These requests were interruptive by nature and altered ongoing individual and time dependent work that were expected to contribute collectively in complex interdependent tasks. Fourth, the intertwined and complex individual media cycling practices involved an increased degree of redundancy insurance through multiple media. This redundancy insurance practice also reduced the impact and effect of the formal and structured lines of communication. These redundancy insurance practices were primarily based on the degree of insecurity among the different members and enacted idiosyncratic practices instead of collective and shared practices. Specifically, it produced a multitude of individual interpretative schemes that should ideally be synchronized to work efficiently.

2) Within the context of the fluid interdependent media practices, the alignment paradox was mainly produced by the practical and cognitive challenges related to organizing the use of the shared digital workspaces more efficiently on the one hand, and the investment of time necessary in terms of developing shared rules and procedures, functional usability, and a shared and continuous updated cognitive understanding of how to use these workspaces on the other hand. None of the leaders and co-workers had the time to structure these workspaces due to the continuous evolving operational tasks that demanded attention. This in turn resulted in more chaotic and asynchronous work practices on the shared workspaces, because of the deterioration of structure and alignment over time. This again accelerated the need for communicating, coordinating, and solving challenges $\mathrm{FtF}$ and through other media, which then again increased the rate of interruptions and continuous concentration break downs, nourishing the negative spiral.

3) The puzzle zone evolved as a necessity to solve complex tasks interdependent in nature, as well as a tool to limit the negative consequences that could evolve from the complexities and alignment challenges due to the individual use of multiple media, such as the consequences of neglecting important information, understanding how specific individual contributions in complex tasks were part of the whole (i.e., maintaining continuous overview), and cycling effectively between the provisional, uncertain, and conflicting conditions part of the puzzle zone. In this puzzle zone no clear answers existed beside the consensus-based shared goal of working towards the ideal state of optimal match between the different operational factors salient at any time that could have an impact on the margins. This fragile notion of "optimal match" produced interpretative ambiguities and different behaviours. The formal strategies and procedures that were necessary in OPCOM supported linear thinking on both the individual and collective level, while the 
practices were characterized by being multidimensional as well as non-linear. This supported the notion of an alignment paradox.

\section{Discussion}

Returning to the research question focusing on the characteristics of multiple media use patterns, this paper identified three practices with patterns of multiple use that are located on both the individual level (the media cycling practices) and the collective level (fluid interdependent media practices and puzzle zone practices). These findings elaborate existing research focusing on multiple media use on the individual level only. Existing research has documented both sequential and concurrent use of multiple media in organizations (Belanger \& Watson-Manheim, 2006), reasons for using multiple media (Stephens, 2005), a toolbox approach for describing the assortment of media available (Woerner, Orlikowski, \& Yates, 2004), designing ecologies for structuring multiple media use (Nardi \& Whittaker, 2002), and conditions and structures related to multiple media use (Belanger and Watson-Manheim, 2006). The valuable insights and knowledge gained in this research largely ignore the patterns of multiple media use in practice.

Belanger and Watson-Manheim (2006) identified two sets of conditions; one set was connected to the media themselves, such as availability and perceived capability of the media, while the other set was related primarily to contextual factors, such as message urgency and message salience. This paper identified three conditions important for patterned multiple media use: access dependent, perceived urgency, and task complexity. As such this paper extends the contextual factors described by Belanger and Watson-Manheim (2006). Further, these conditions were important as drivers for the multiple media use patterns among the respondents, while Belanger \& WatsonManheim (2006) relate their conditions to underlying structures of multiple media use. Their focus on structures implies a more static view - or something arranged in a definite pattern of organization. Patterns, on the other hand, are more dynamic. In OPCOM these patterns evolved due to the non-linear and complex working environment. This paper also extends existing research by suggesting five different multiple media use patterns as part of media cycling practices on the individual level: rotation strategy, monitoring, coercive use, habitual use, and redundancy insurance. The label used to describe the last pattern was adopted from Sitkin, Sutcliffe, and BarriosChoplin (1992), and also identified by Belanger and Watson-Manheim (2006) in their research.

The media toolbox concept suggested by Woerner, Orlikowski \& Yates (2004) is a useful label for describing the multiple media that are available in an organization, in which media will be used depending on what needs to be communicated. The multiple media use in OPCOM was characterized by a high degree of interdependency and individual differences in the ways they used multiple media. This was especially evident in the fluid interdependent media practices, in which the use of shared systems suffered because of differences in cognitive understanding on how to use these systems as well as actual use. This was due to the high pressure and unpredictable nature of operational work tasks that could alter individual work and require collaborate work, as described in both the fluid interdependent media practices as well as puzzle zone practices. As such, designing media ecologies as cost effective solutions for communication (Nardi \& Whittaker, 2002) is complicated by work tasks that are unpredictable and in part uncontrollable in nature, as well as the fact that such a designing process requires a "time out" to evaluate and restructure existing multiple media practices. The three conditions identified in this paper, suggest that designing such media ecologies is a difficult endeavour.

The puzzle zone practices were the main arenas in OPCOM to coordinate and align individual multiple media practices. This concept resembles the notion of a "trading zone" introduced by Galison (1999) and elaborated by Kellogg et al. (2006) focusing primarily on coordination, and Nardi and Whittaker's (2002) "communication zones" emphasizing the social fields we create in 
which communication takes place and where information exchange is the goal of communication. The "puzzle zone" concept introduced in this paper differs by emphasizing the solution oriented dimensions of the practices, while at the same time acknowledging that both coordination and information exchange is important and embedded within the puzzle zone as well. These puzzle zones could occur spontaneously within or between the three teams, as well as on the formally defined arena the operational meetings represented, and emerged as a control mechanism in order to manage a continuous changing work environment. These findings on the collective level extend existing research on individual multiple media use and highlight the importance of approaching this use on the collective level as well. The use of multiple media are characterized by a low degree of technical integration due to the fact that multiple media both in terms of hardware and software are designed by different companies, utilizing different usability standards, as well as differences in terms of underlying philosophy. This enacts multiple media practices that are more complex, fluid, idiosyncratic, and diversified in terms of shared interpretative repertoires and actual behavior than identified in existing research.

The second research question addressed the limited focus there has been on the consequences of multiple media use in organizations (Belanger \& Watson-Manheim, 2006). This paper introduces the concept of alignment paradox embedded within practices and with consequences for organizational goals, strategies, routines, and procedures. This produces a constant tension manifested on both the individual as well as the collective level. Although alignment challenges were in part identified by the organizational members through reflexive monitoring (Fuchs, 2003), the alignment paradox seems to have evolved as a consequence of the need for flexibility in OPCOM, as well as the increasing number of tasks, their complexity, structuring the shared digital workspaces, and the need to use multiple media in combinations to work efficiently. This, in turn, results in an increased permeability of boundaries (Browning, 2004). Furthermore, the alignment paradox has evolved gradually over time and has an ontological and immanent character, which is not easily identified and subject to control. The alignment paradox's immanence in OPCOM's multiple media practices is stable at its core but produces instability and continuous change in work practices. This alignment paradox is "re-creative" (Fuchs, 2003), and does not exist outside actions.

The alignment paradox may be seen as a structure that has evolved unintentionally, and, consequently, it will both constrain and enable different actions. Such practices will only achieve temporary "stabilization" because of the continuous redefinition and modification of technology and use patterns, as well as changes in the context. Furthermore, technologically mediated work requires more standardized and interdependent artefacts because of its complexity (Orlikowski, 2000). The findings presented in this paper show that the unpredictable nature of operational work and intense time pressure does not allow for work processes that contribute to these standardized and interdependent artefacts. This increases the use of multiple media and contributes to a deterioration of structure, which in turn allows for the continuous existence of the alignment paradox. Within this context one may state that the organizational media alter both individual and higher level organizational processes. These processes involve new and cognitive work practices, requiring efforts to interpret and resolve (Rice \& Schneider, 2005).

The findings also elaborate the existing perspectives on misalignments by proposing the immanence of an alignment paradox, which may be more or less salient due to disconfirming events (Majchrzak et al., 2000), but not solved in order to align decision processes and outcomes. The findings also question the idea that cycles of misalignments gradually dissolve over time (Leonard-Barton, 1988), as well as the view that alignments will occur through discontinuous adaptations (Tyre \& Orlikowski, 1994). The continuous co-evolution of discrete media, different individual media practices, and the intersection with fluid interdependent media practices, and puzzle zone practices, complicates and contributes to a state in which integration of the multiple media 
as part of the media toolbox, as well as the coordination of individual and collective work practices mediated by these different media, results in diametrical opposed requirements between structural conditions and actual practices. This nourishes the alignment paradox.

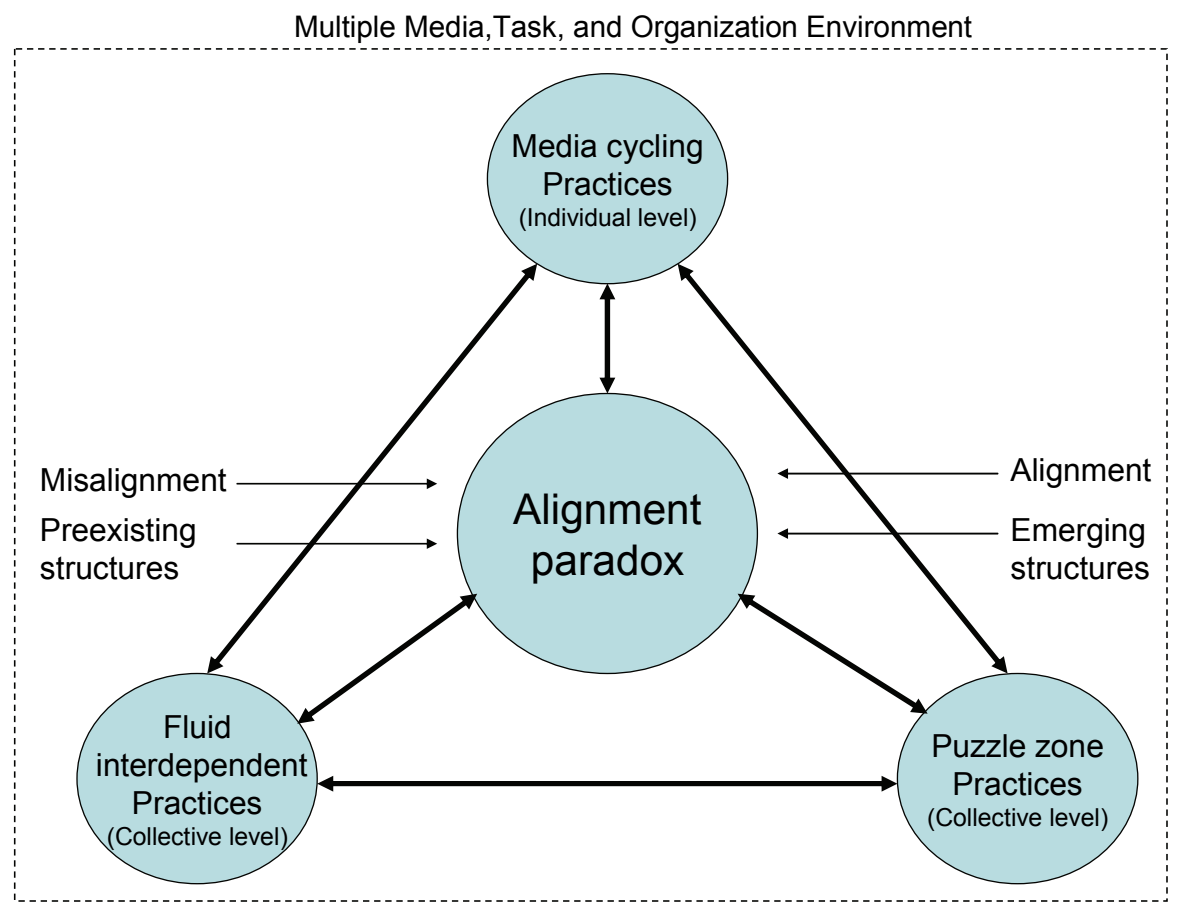

Figure 1: Multiple Media Practices Leading to an Alignment Paradox

Figure 1 provides a visualization and overview of the main findings in this study. The three multiple media practices are highly integrated and influenced by each other. Individual multiple media practices will often become part of collective activities as indicated in the findings and elaborates existing research focus on the individual level. In an "ideal" organization there would be a movement from a state of misalignment to becoming aligned. This implies that pre-existing and perhaps ineffective structures are left behind, letting new and more effective structures emerge. The findings in this study show that multiple media use is non-linear depending on individual and often idiosyncratic use patterns, contextual factors, and task characteristics. Residuals from past individual and collective practices influence how work is conducted currently and challenge the organizing of work practices sought in the future. More specifically, the pre-existing structures are an integrated part of emerging structures and, therefore, enact different structures than those expected. This contributes to maintaining the alignment paradox.

Although each individual in OPCOM had specific responsibilities within their team, and there were formalized distinctions between the three teams (sales, logistics and back office), the nature of operative work tasks would often create confusion of responsibility between them. This was simply because solving many tasks required bits of information from each of the teams. These work tasks were not always clearly defined formally from the outset due to their unpredictable and ambiguous nature. The norm within OPCOM was that operative work had priority. This implied that analytical work related to revision of strategies, work roles, document descriptions, and shared work practices were put on hold. This contributed to strengthen the negative impact of idiosyncratic media cycling patterns on the individual level, as well as the contradictory, interruptive, and sub-optimal use patterns characterizing the fluid interdependent media practices on the collective level. In order to handle the "operative reality" the formalized operative meetings twice 
a week functioned as a way to coordinate and solve work tasks among individuals and teams, and to reduce the negative effects emerging from sub-optimal communication. These puzzle zones emerged in other informal contexts as well, in order to handle both the interrelatedness and ambiguous nature of work within the department.

\section{Conclusion}

Existing research has provided valuable insight on individual multiple media use, although primarily based on research designs approaching users detached from the user context. The findings in this paper go beyond the structural properties of multiple media use identified by existing research by identifying patterns in the context of the users. Further, the findings suggest that an important part of multiple media is positioned in the intersection between individual and collective practices. The findings also elaborate existing knowledge by focusing on consequences of multiple media use and by suggesting that, in the intersection between individual and collective multiple media use practices, challenges of aligning occur as a continuous state producing an alignment paradox.

The strength of conducting a case study like this is related to the closeness and length of time observing and interviewing the respondents (Majchrzak et al., 2000). Similar to the study of Kellogg et al. (2006), this case study was exploratory and related to one firm with "distinctive characteristics". OPCOM is an operational department with high-end users, and as such it serves as a "magnifier" of issues related to the use of multiple media (Sørnes, 2005). OPCOM might have a different organizational culture compared to other organizations, which is important to consider when evaluating the findings from this study. Further, the operative reality OPCOM worked within influenced the multiple media use, which might differ from organizations in which operative work is not as salient.

Future research should elaborate and explore practices related to use of multiple media, in order to highlight how the findings in this paper relate to other organizational contexts. Of special interest is the notion of puzzle zone practices, and how media in combinations are used within such practices. Further, the concept of the alignment paradox as well as its consequences should be elaborated to identify in depth its existence, conditions, and consequences. It is expected that living with such complexities triggered by multiple media practices also have strong emotional as well as cognitive dimensions that should be explored. Finally, future research should focus on the methodological challenge of studying multiple media use in context.

\section{Practical implications for organizations}

Multiple media use in organizations represents a movement from "push" oriented organizational forms, in which management is more in control, towards "pull" based, where employees are taking charge to a greater extent. In organizations today it becomes increasingly difficult for management to predict and control organizational behavior because the non-linear nature of multiple media use generates practices different from those inscribed and expected from management through strategy documents, rules, and procedures. Such formalized guidelines are primarily based on single media perspectives and will seldom deliver expected effects due to crossover use of different media based on other criteria than those set by management. Multiple media use in organizations resurrects the old Gestalt psychological notions of approaching every phenomenon holistically.

Practices will often emerge based on a need to work creatively and flexibly in order to handle unpredictable operational work events. Understanding how multiple media is used in the organization and identifying how this use generates different practices that intersect is important knowl- 
edge to consider when implementing new strategies as well as technology in the organization. Management as well as employees can use the identified conditions and patterns presented in this paper as lenses to approach multiple media practices in their own organization. This could improve the understanding and management of multiple media use within the organization.

Further, acknowledging that an alignment paradox is part of the everyday media practices implies that perspectives on organizational planning and execution should change from a notion of control to influence. More specifically, in some instances it might be more beneficial to find ways of living with and acknowledge such a paradox, instead of using energy trying to solve it. Leaders and co-workers could also benefit from becoming more self-reflexive about how multiple media use in highly complex and unpredictable work settings might trigger different emotional states influencing work. Learning how to handle unpredictability, managing unfinished tasks existing in parallel on an continuous basis, having strategies for balancing operational and analytical tasks, handling the interdependent nature of ongoing work tasks, and understanding how sequential and parallel use of multiple media influence the multiple tasks at hand becomes increasingly important. This implies that individuals have to find effective ways to handle the emotional and cognitive challenges of working in such environments.

Management should also acknowledge that the effective use of shared digital systems is not only based on the usability of single media. A shared cognitive understanding regarding how to use these media sequentially and concurrently becomes important as well. It is necessary for teams, departments, and organizations to implement strategies that are continuous on how to maintain a shared understanding of multiple media use. This is important because idiosyncratic practices or personal habits have a tendency to re-appear destabilizing the shared understanding of how to use the different media. Neglecting such processes will increase the negative impact produced by suboptimal use patterns. Further, understanding how certain work practices can be paradoxical in nature might help both individuals and organizations to internalize, integrate, and implement cognitive and emotional strategies to handle such complexities.

\section{References}

Bellotti, V., Ducheneaut, N., Howard, M., Smith, I., \& Grinter, R. E. (2005). Quality versus quantity: Email-Centric task management and its relation with overload. Human-Computer Interaction, 20, 89138.

Belanger, F., \& Watson-Manheim, M. B. (2006). Virtual teams and multiple media: Structuring media use to attain strategic goals. Group Decision and Negotiation, 15, 299-321.

Breakwell, G. M., Hammond, S., \& Fife-Schaw, C. (1997). Research Methods in Psychology. London: Sage Publications.

Browning, L. D. (2004)..Information \& communication technology in action: Linking theory \& narratives of practice. Denmark: Copenhagen Business School Press.

Charmaz, K. (2003). Grounded theory. In J. A. Smith (Ed.), Qualitative psychology: A practical guide to research methods. London: Sage Publications.

DeSanctis, G., \& Poole, M. S. (1994). Capturing the complexity in advanced technology use: Adaptive structuration theory. Organization Science, 5(2), 121-147.

Esterberg, K. G. (2001). Qualitative methods in social research. New York: McGraw-Hill.

Fuchs, C. (2003). Structuration theory and self-organization. Systemic Practice and Action Research, 16(2), 133-167.

Galison, P. (1999). Trading zone: Coordinating action and belief. In M. Biagioli \& P. Galison (Eds.), The science study reader. New York: Routledge. 
Giddens, A. (1984). The constitution of society. Cambridge: Polity Press.

Glaser, B. G., \& Straus, A. L. (1999). The discovery of grounded theory: Strategies for qualitative research. New York: Aldine De Gruyter.

Kellogg, K. C., Orlikowski, W. J., \& Yates, J. (2006). Life in the trading zone: Structuring coordination across boundaries in postbureaucratic organizations. Organization Science, 17(1), 22-44.

Leonard-Barton, D. (1988). Implementation as mutual adaptation of technology and organization. Research Policy, 17, 251-267.

Ling, R. (2005). The socio-linguistics of SMS: An analysis of SMS use by a random sample of Norwegians. In R. Ling \& P. E. Pedersen (Eds.), Mobile communications: Re-negotiation of the social sphere. London: Springer.

Locke, K. (2001). Grounded theory in management research. London: Sage Publications.

Majchrzak, A., Rice, R. E., Malhotra, A., King, N., \& Ba, S. (2000). Technology adaptation: The case of a computer-supported inter-organizational virtual team. MIS Quarterly, 24(4), 569-600.

Martin, D., \& Rouncefield, M. (1993). Making the organization come alive: Talking through and about the technology in remote banking. Human-Computer Interaction, 18, 111-148.

Nardi, B. A., \& Whittaker, S. (2002). The place of face-to-face communication in distributed work. In P. J. Hinds \& S. Kiesler (Eds.), Distributed work. Cambridge: MIT Press.

Orlikowski, W. J. (1992). The duality of technology: Rethinking the concept of technology in organizations. Organization Science, 3(3), 398-427.

Orlikowski, W. J. (2000). Using technology and constituting structures: A practice lens for studying technology in organizations. Organizational Science, 11(4), 404-428.

Peters, L. P. (2006). Conceptualizing computer-mediated communication technology and its use in organizations. International Journal of Information Management, 26(2), 142-152.

Pozzebon, M., \& Pinsonneault, A. (2005). Challenges in conducting empirical work using structuration theory: Learning from IT research. Organization Studies, 26(9), 1353-1376.

Prus, R. (1996). Symbolic interaction and ethnographic research. Albany: State University of New York Press.

Quan-Haase, A., Cothrel, J., \& Wellman, B. (2005). Instant messaging for collaboration: A case study of a high-tech firm. Journal of Computer-Mediated Communication, 10(4), article 13. Retrieved July 15, 2006, from $\mathrm{http}: / / \mathrm{jcmc}$.indiana.edu/vol10/issue4/quan-haase.html

Rice, R. E., \& Schneider, S. (2005). Organizational information technology: From paper to electronic desktops. In C. Lin \& D. Atkin (Eds.), Communication technology and social change: Theory, effects, and application. New York: Lawrence Erlbaum Associates.

Robson, C. (1997). Real world research: A resource for social scientist and practitioner -researcher. Oxford: Blackwell Publishers.

Sandfort, J. R. (2003). Exploring the structuration of technology within human service organizations. $A d-$ ministration \& Society, 34(6), 605-631.

Short, J., Williams, E., \& Christie, B. (1976). The social psychology of telecommunication. London: John Wiley \& Sons.

Sitkin, S. B., Sutcliffe, K. M., \& Barrios-Choplin, J. R. (1992). A dual-capacity model of communication media choice in organizations. Human Communication Research, 18(4), 563-598.

Sivunen, A. \& Valo, M. (2006). Team leaders' technology choice in virtual teams. IEEE Transactions on Professional Communication, 49(1), 57-68.

Soernes, J. O. (2005). Information and communication technologies and practice. A study of advanced users in the workplace in Norway and the United States. Unpublished doctoral thesis at the department of 
industrial economics and technology management, Norwegian University of Science and Technology, Trondheim, Norway.

Stephens, K. K. (2005). Combinatorial media use in organizations: Understanding why people use more than one medium to communicate. Unpublished doctoral thesis at the Faculty of the Graduate school, University of Texas.

Stephens, K. K., Browning, L. D., Sørnes, J. O., \& Sætre, A. S. (2005). A reflexive model of ICT practices in organizations. Paper presented at the 52nd Annual Conference of the International Communication Association, Seoul, Korea.

Tam, J., \& Greenberg, S.( 2006). A framework for asynchronous change awareness in collaborative documents and workspaces. International Journal of Human-Computer Science, 64(7), 583-598.

Trevino, L. K., Lengel, R. H., \& Daft, R. L. (1987). Media symbolism, media richness, and media choice in organizations. Communication Research, 14(5), 553-574.

Tyre, M. J., \& Orlikowski, W. (1994). Windows of opportunity: Temporal patterns of technological adaptation in organizations. Organization Science, 5(1), 98-118.

Vreede, G. J. \& Guerrero, L. A. (2006). Theoretical and empirical advances in groupware research. International Journal of Human-Computer Studies, 64(7), 571-572.

Walther, J. B., \& Parks, M. R. C. (2002). Cues filtered out, cues filtered in: Computer-mediated communication and relationships. In M. L. Knapp \& J. A. Daly (Eds.). Handbook of interpersonal communication. California: Sage Publications.

Woerner, L. S., Orlikowski, W. J., \& Yates, J. (2004). The media toolbox: Combining media in organizational communication. Paper presented at the Academy of Management Conference, New Orleans, LA.

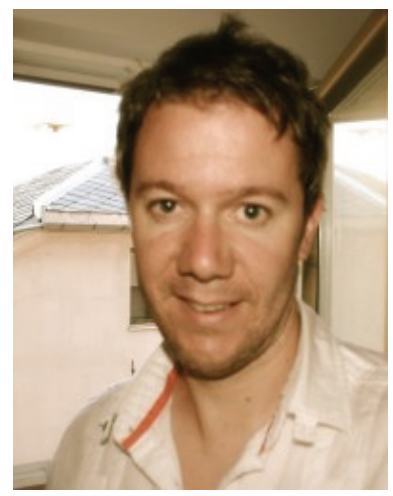

\section{Biography}

Keith Munkejord teaches organizational communication and methods at the Norwegian University of Science and Technology, Department of Psychology. He investigates how the use of multiple media impacts communication in organizations. He has worked several years as a consultant in organizations with internal communication as his special field of interest. 